\title{
ÁCIDO SULFÚRICO NA SUPERAÇÃO DA DORMÊNCIA DE UNIDADES DE DISPERSÃO DE JUAZEIRO (Zizyphus joazeiro Mart.) ${ }^{1}$
}

\author{
Edna Ursulino Alves ${ }^{2}$, Riselane de Lucena Alcântara Bruno ${ }^{2}$, Ademar Pereira de Oliveira ${ }^{2}$, Adriana
}

Ursulino Alves ${ }^{3}$ e Anarlete Ursulino Alves ${ }^{4}$

\begin{abstract}
RESUMO - O Zizyphus joazeiro Mart. apresenta redução sensível no número de indivíduos em seu ambiente natural devido, entre outras causas, à ocorrência de dormência exógena da unidade de dispersão (impermeabilidade à água). Avaliou-se o efeito do período de imersão $(0,30,60,90,120$ e $150 \mathrm{~min})$ dessas unidades de dispersão, em ácido sulfúrico (98\%), na emergência e vigor das sementes (primeira contagem, índice de velocidade e tempo médio de emergência, altura e massa seca de plantas). O experimento foi realizado em casa de vegetação, utilizando-se o delineamento inteiramente ao acaso, com seis tratamentos e quatro repetições. O pré-condicionamento das unidades de dispersão de Zizyphus joazeiro Mart., em ácido sulfúrico concentrado, mostrou-se eficiente na superação da dormência dessa espécie, promovendo aumento na porcentagem e velocidade de emergência, primeira contagem de emergência, na altura e massa seca de plantas e redução no tempo médio para emergência. A eficiência do tratamento químico com ácido sulfúrico concentrado depende do período de imersão, sendo a faixa entre 74 e 115 min mais adequada para proporcionar maiores porcentagens de emergência e de vigor.
\end{abstract}

Palavras-chave: Sementes, germinação, vigor e escarificação química.

\section{THE USE OF SULFURIC ACID TO BREAK DISPERSAL UNIT DORMANCY OF Zizyphus joazeiro Mart.}

\begin{abstract}
Zizyphus joazeiro Mart. trees have been declining in number in their natural habitat due to, among other reasons, the occurrence of dormancy of dispersal units (water impermeability). The effect of the immersion time $(0,30,60,90,120$ and 150 minutes) of Zizyphus joazeiro Mart. dispersal units in concentrated sulfuric acid (95-98\%) was evaluated through the emergency and vigor (first count, speed index and mean emergence time, plant height and dry matter weight). The experiment was performed under greenhouse conditions, with a completely randomized experimental design, six treatments and four replications. The pre-conditioning of Zizyphus joazeiro Mart. dispersal units with immersion in concentrated sulfuric acid was efficient for breaking the seed dormancy and also for increasing the emergence percentage and speed, the emergence first count, plant height and dry matter weight and reduction in the mean emergence time. The efficiency of this chemical treatment, with concentrated sulfuric acid, was shown to be dependent on the immersion time, being the most suitable to provide larger emergency percentages and vigor between 74 and 115 minutes.
\end{abstract}

Keywords: seeds, germination, vigor and chemical scarification.

\footnotetext{
${ }^{1}$ Recebido em 13.02.2004 e aceito para publicação em 10.11.2005.

${ }^{2}$ Centro de Ciências Agrárias da UniversidadeFederal da Paraíba, Cx. Postal 02, 58.397-000 Areia-PB.E-mail:<ursulinoalves@ hotmail.com>.

${ }^{3}$ Programa de Pós-Graduação em Agronomia. CCA-UFPB, Areia-PB.

${ }^{4}$ Curso de Graduação em Agronomia. CCA-UFPB, Areia-PB.
} 


\section{INTRODUÇÃO}

O juazeiro (Zizyphus joazeiro Mart.), Rhamnaceae, conhecido como juá, juá-fruta e laranja-de-vaqueiro, é encontrado no Nordeste do país, especialmente nas caatingas e campos abertos do polígono da seca. A madeira é empregada em construções rurais, marcenaria, para lenha, confecção de moirões e de carvão. A árvore proporciona sombra, além de possuir qualidades ornamentais, podendo ser empregada com sucesso no paisagismo em geral, especialmente na arborização de ruas e jardins. Os frutos são comestíveis, ricos em vitamina $\mathrm{C}$ e amadurecem entre junho e julho. A emergência das plântulas ocorre entre 70-100 dias, e a porcentagem final é geralmente muito baixa, fazendose necessário o desenvolvimento de técnicas para superação da resistência mecânica dos endocarpos (LORENZI, 2000).

A impermeabilidade do tegumento à água é um tipo de dormência bastante comum e está associada a espécies de diversas famílias botânicas, sendo constatada com maior freqüência em sementes de espécies Leguminosae, Malvaceae, Geraniaceae, Chenopodiaceae, Convolvulaceae, Solanaceae e Liliaceae (KRAMER e KOZLOWSKI, 1972; POPINIGIS, 1985; CÍCERO, 1986). Segundo Carvalho e Nakagawa (2000), esse tipo de dormência é encontrado com maior freqüência em Leguminosae. Conforme levantamento realizado por Rolston (1978), de 260 espécies de leguminosas examinadas, cerca de $85 \%$ apresentavam sementes com tegumento total ou parcialmente impermeável à água.

Em ambiente natural, essa dormência é quebrada por processos de escarificação, a qual consiste em qualquer tratamento que resulte na ruptura ou enfraquecimento do tegumento, permitindo a entrada de água e gases e, assim, dando início ao processo germinativo (MAYER e POLJAKOFF-MAYBER, 1989). Nesse ambiente, a escarificação pode ocorrer pelo aquecimento úmido ou seco do solo, por temperaturas alternadas, permitindo, assim, a entrada de água para o interior da semente. Esse processo pode ocorrer, também, pela ação de ácidos quando da ingestão das sementes por animais dispersores, além da ação dos microrganismos do solo (VAZQUEZ-YANES e OROZCOSEGOVIA, 1993).

Em laboratório, foram desenvolvidos diversos métodos, visando à superação desse tipo de dormência, como imersão em ácidos, bases fortes, álcool, água

R. Árvore, Viçosa-MG, v.30, n.2, p.187-195, 2006 oxigenada, água fria ou quente, pré-secagem, desponte e impactos sobre superfície sólida, entre outros (MAYER ePOLJAKOFF-MAYBER, 1989; PEREZePRADO, 1993). No entanto, a aplicabilidade e eficiência desses tratamentos dependem do tipo e grau de dormência, que variam entre as espécies.

Segundo Eira et al. (1993), todos esses tratamentos apresentam vantagens e desvantagens, de forma que cada um deles deve ser estudado, levando-se em conta, também, o custo efetivo e sua facilidade de execução. Além disso, para um mesmo lote, pode haver sementes com diferentes níveis de dormência. Assim, o método empregado deve ser efetivo na superação da dormência, sem prejudicar as sementes que apresentam dormência menos acentuada.

A eficiência do ácido sulfúrico foi comprovada na superação da dormência de sementes de Prosopis alba, $P$. chilensis, $P$. flexuosa e $P$. tamarugo (LOPEZ e AVILES, 1988), Leucaena leucocephala (Lam.) de Wit. (DUGUMA et al., 1988), Acacia bonariensis Gill. e Mimosa bimucronata (D.C.) O.K. (FERREIRA et al., 1992), Cassia sieberiana D.C. (TODD-BOCKARIE et al., 1993), Enterolobium contortisiliquum (Vell.) Morong (EIRA et al., 1993), Senna macranthera (Colladon) Irwin \& Barneby (SANTARÉM e AQUILA, 1995; LEMOSFILHO et al., 1997), Ornitophus compressus e O. pinatus (FU et al., 1996) e Cassia excelsa Schrad (JELLER e PEREZ, 1999).

Diante do exposto, o trabalho teve por objetivo avaliar a eficiência do ácido sulfúrico concentrado na superação da dormência de unidades de dispersão de Zizyphus joazeiro Mart.

\section{MATERIAL E MÉTODOS}

O trabalho foi realizado em casa de vegetação do Departamento de Fitotecnia do Centro de Ciências Agrárias da Universidade Federal da Paraíba, em Areia, PB, a 6 $58^{\prime} 12$ ' ' de latitude sul e 35 42 ' $15^{\prime}$ " de longitude oeste de Greenwich. A região encontra-se numa altitude de 574,62 m, com temperatura média anual entre 23$24^{\circ} \mathrm{C}$ e precipitação de $1.400 \mathrm{~mm}$.

Os frutos de Zizyphus joazeiro Mart. foram colhidos diretamente das árvores no Município de Barra de Santa Rosa, PB, e em seguida levados para o Laboratório de Análise de Sementes, onde foram despolpados manualmente, restando parte do fruto, o endocarpo, que fica aderido ao tegumento da semente, e submetidos 
à fermentação por cinco dias, para a retirada de mucilagem. Decorrido esse período, foram lavados com água corrente, sob peneira de arame, e postos para secar à sombra por cinco dias.

As unidades de dispersão constituídas de endocarpo + semente foram imersas em ácido sulfúrico concentrado (densidade de 1,84 e pureza de 95-98\%) e constantemente revolvidas com um bastão de vidro, objetivando uniformizar a sua ação abrasiva em diferentes períodos de imersão $(30,60,90,120$ e 150 min). Decorridos os períodos preestabelecidos, as unidades de dispersão foram lavadas em água corrente por $10 \mathrm{~min}$, para que o ácido sulfúrico concentrado fosse totalmente retirado.

Depois de submetidas aos tratamentos, as unidades de dispersão foram semeadas em bandejas plásticas perfuradas no fundo, entre areia previamente peneirada e esterilizada em autoclave, umedecida com quantidade de água equivalente a $60 \%$ da capacidade de retenção. Avaliaram-se as seguintes características: emergência - foram utilizadas 100 das unidades de dispersão por tratamento, divididas em quatro subamostras de 25 . As contagens do número de sementes germinadas iniciaram-se aos 16 e estenderam-se até os 118 dias após a semeadura, à exceção da testemunha, cuja primeira contagem só foi possível aos 54 dias após o semeio. O critério utilizado foi o de plântulas normais que apresentavam as estruturas essenciais perfeitas (BRASIL, 1992), sendo os resultados expressos em porcentagem; primeira contagem de emergência - correspondente à porcentagem acumulada de plântulas normais, com valores registrados aos 26 (tratamentos de escarificação ácida) e 54 (testemunha) dias após o início do teste; índice de velocidade de emergência (IVE) - foram realizadas contagens diárias, durante 118 dias, das plântulas normais, sendo o índice calculado conforme a fórmula proposta por Maguire (1962); tempo médio e freqüência relativa de emergência - avaliados de acordo com Labouriau e Valadares (1976); comprimento de plântulas - no final do teste de emergência, as plântulas normais de cada repetição foram medidas com o auxílio de uma régua graduada em centímetros, sendo os resultados expressos em centímetros por plântula; massa seca das plântulas - após a contagem final no teste de emergência, as plântulas anteriormente medidas foram submetidas à secagem em estufa regulada a $65^{\circ} \mathrm{C}$ até atingirem peso constante.
O delineamento experimental utilizado foi o inteiramente ao acaso, constando de seis tratamentos. Os dados foram submetidos a análises de variância e de regressão polinomial. Na análise da regressão foram testados os modelos linear, quadrático e cúbico, sendo selecionado para explicar os resultados aquele com maior valor do coeficiente de determinação $\left(\mathrm{R}^{2}\right)$.

\section{RESULTADOS E DISCUSSÃO}

Os dados referentes à porcentagem de emergência encontram-se na Figura 1. A regressão polinomial dos períodos de exposição ao ácido sulfúrico concentrado apontou um modelo quadrático, ou seja, a porcentagem de emergência cresceu à medida que aumentou o tempo de imersão das unidades de dispersão no ácido sulfúrico concentrado, atingindo o máximo de $68 \%$ em 74 min. Para Rubus idaeus L., Maeda e Marcondes Coelho (1995) verificaram que a interação entre estratificação (30 ou 60 dias) mais escarificação com ácido sulfúrico concentrado por 120 min foi o tratamento mais eficaz para superação da resistência mecânica dos endocarpos, proporcionando porcentual máximo de germinação de apenas $32 \%$.

Em sementes de Cassia excelsa, Schrad et al. (1999) obtiveram os maiores porcentuais de germinação com o tratamento de imersão em ácido sulfúrico concentrado por $25 \mathrm{~min}$, o qual não diferiu estatisticamente dos 30 min. Segundo Santarém e Aquila (1985), o amolecimento do tegumento das sementes parece ser resultante da remoção da cutícula e exposição das camadas de macroesclereídes, permitindo, assim, permeabilidade mais homogênea.

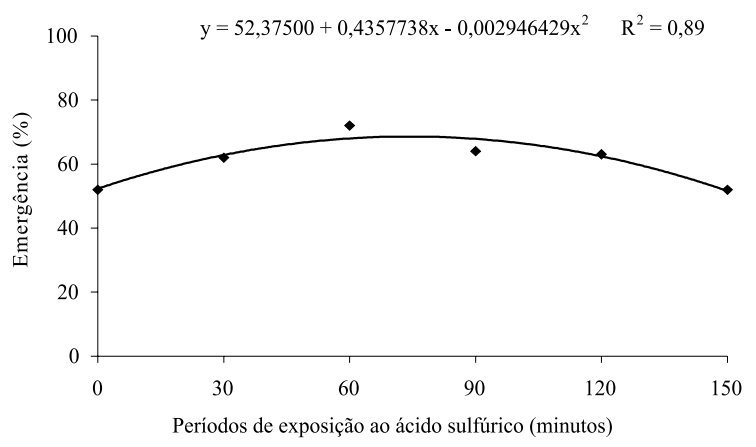

Figura 1 - Emergência de plântulas de Zizyphus joazeiro Mart., após a superação da dormência das unidades de dispersão com ácido sulfúrico concentrado.

Figure 1-Emergence of Zizyphus joazeiro Mart. seedlings, after breaking dormancy of dispersal units with concentrated sulfuric acid.

R. Árvore, Viçosa-MG, v.30, n.2, p.187-195, 2006 
Aumentando o período de imersão das unidades de dispersão no ácido sulfúrico concentrado, verificouse redução na porcentagem de emergência. Esse fato pode estar relacionado aos efeitos danosos do ácido sulfúrico no embrião, uma vez que Rolston (1978) relatou que a escarificação química propicia a degradação do tegumento e o aumento do período de imersão pode causar ruptura das células essenciais, o que favorece as injúrias mecânicas e a invasão de fungos, prejudicando, assim, a emergência.

Sampaio et al. (2001), estudando os efeitos da escarificação com ácido sulfúrico sobre a porcentagem de emergência de plântulas de sucupira-preta (Bowdichia virgilioides H.B.K.), também obtiveram melhor ajuste dos dados ao modelo quadrático, em que a maior porcentagem de emergência (70-80\%) ocorreu com um período de imersão entre 8 e $11 \mathrm{~min}$. Também, Bruno et al. (2001) indicaram o tratamento de sementes de Mimosa caesalpiniaefolia Benth. com ácido sulfúrico por 10 ou 13 min como o mais eficiente para superação da dormência.

Os valores médios referentes ao vigor, determinado pela primeira contagem de emergência, são apresentados na Figura 2. À semelhança da porcentagem de emergência, os dados também se ajustaram ao modelo quadrático, em que o valor máximo (50\%) foi obtido quando as unidades de dispersão ficaram imersas no ácido sulfúrico concentrado por um período de $110 \mathrm{~min}$. Também, Bruno et al. (2001) constataram a eficiência do ácido sulfúrico no tratamento pré-germinativo de sementes de Mimosa caesalpiniaefolia Benth., cujo maior valor na primeira contagem de germinação ocorreu com a imersão por períodos entre 10 e $13 \mathrm{~min}$.

Quanto ao índice de velocidade de emergência (Figura 3), também houve melhor ajuste dos dados ao modelo quadrático, em que o tratamento de imersão por 100 min no ácido sulfúrico concentrado foi responsável pelo vigor máximo das sementes $(0,51)$. Em sementes de Caesalpinia ferrea Mart. ex Tul. var. leiostachya Benth., Lopes et al. (1998) observaram maior velocidade de germinação quando as sementes foram imersas no ácido sulfúrico concentrado por 60 min. Já em sementes de Bowdichia virgilioides H.B.K. Sampaio et al. (2001) constataram maior velocidade de emergência das plântulas quando as sementes ficaram imersas no ácido por períodos entre 8 e $11 \mathrm{~min}$.
Resultados semelhantes foram obtidos em Mimosa caesalpiniaefolia Benth., em que a imersão das sementes em ácido sulfúrico concentrado por $13 \mathrm{~min}$ proporcionou os maiores índices de velocidade de germinação (BRUNO et al., 2001).

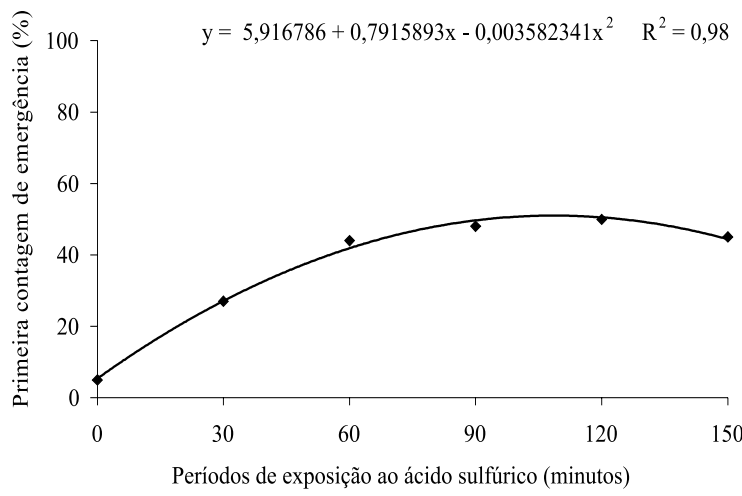

Figura 2 - Vigor de sementes Zizyphus joazeiro Mart. (primeira contagem de emergência), após a superação da dormência das unidades de dispersão com ácido sulfúrico concentrado.

Figure 2 - Vigor of Zizyphus joazeiro Mart. seeds (first emergence count), after breaking dormancy of dispersal units with concentrated sulfuric acid.

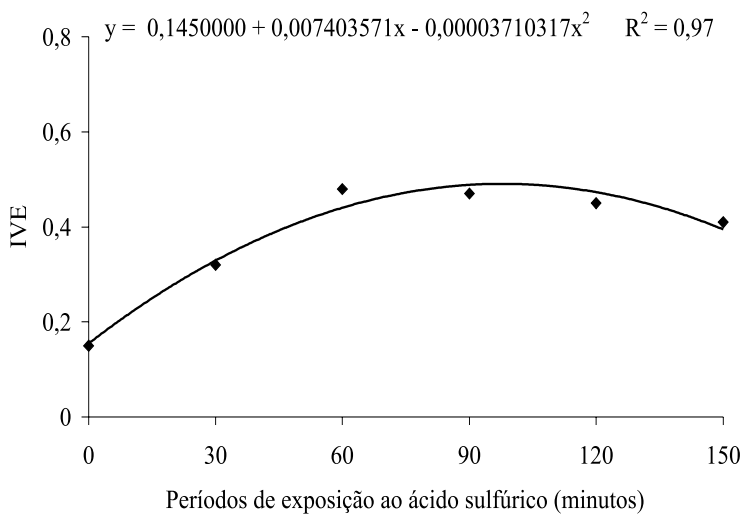

Figura 3 - Vigor de sementes de Zizyphus joazeiro Mart. (índice de velocidade de emergência - IVE), após a superação da dormência das unidades de dispersão com ácido sulfúrico concentrado.

Figure 3 - Vigor of Zizyphus joazeiro Mart. seeds (index of emergence speed - IES), after breaking dormancy of dispersal units with concentrated sulfuric acid. 
A utilização do ácido sulfúrico concentrado se mostrou eficaz em aumentar a velocidade de germinação em sementes de Enterolobium contortisiliquum (Vell.) Morong. (CANDIDO et al., 1982), Bertholletia excelsa H.B.K. (FRAZÃO et al., 1984), Leucaena leucocephala (Lam.) de Wit. (PASSOS et al., 1988), Mimosa caesalpiniaefolia Benth. (MARTINS et al., 1992), Prosopis juliflora (SW.) DC. (BASTOS et al., 1992), Copaifera langsdorffii Desf. (PEREZ e PRADO, 1993), Mimosa bimucronata (DC.) O. Kuntze (RIBAS et al., 1996), Peltophorum dubium Taub. (PEREZ et al., 1999) e Bauhinia monandra Britt (ALVES et al., 2000).

Conforme dados da Figura 4, à semelhança do índice de velocidade de emergência, as médias do tempo médio para emergência se ajustaram ao modelo quadrático, em que os menores valores (81,22 dias) foram obtidos com a imersão das unidades de dispersão em ácido sulfúrico concentrado por um período de $115 \mathrm{~min}$. Também, Alves et al. (2000) verificaram que o tratamento com ácido sulfúrico concentrado reduziu o tempo médio para germinação das sementes de Bauhinia monandra Britt.

Na Figura 5 estão os polígonos de frequência relativa de emergência de plântulas de Zizyphus joazeiro Mart., após a imersão em ácido sulfúrico concentrado por diferentes períodos, em que a emergência das plântulas se distribuiu de forma diferenciada, nos pré-tratamentos utilizados, ao longo do tempo. Os polígonos de frequiência relativa são claramente unimodais apenas nos tratamentos de imersão em ácido sulfúrico concentrado pelos períodos de 90 e $120 \mathrm{~min}$, enquanto nos demais se tornam claramente polimodais.

A impermeabilidade do tegumento permite o prolongamento do tempo de vida das sementes, podendo formar um banco de sementes persistente no solo pelo fato de distribuir a germinação no tempo e no espaço, o que pode aumentar as chances de essas sementes encontrarem condições para o estabelecimento das plântulas em condições naturais. No entanto, tornase desvantajoso quando se deseja uma emergência rápida e uniforme, em processos de utilização de sementes em grande escala (ROLSTON, 1978).

As unidades de dispersão intactas (testemunha), como também aquelas imersas no ácido sulfúrico concentrado por 30,60 e $150 \mathrm{~min}$, apresentaram emergência distribuída ao longo do tempo de incubação, característica importante para a sobrevivência da espécie em condições naturais. Resultados semelhantes foram obtidos por Cavalcante e Perez (1996) com sementes de Leucaena leucocephala (Lam.) de Wit., em que a germinação distribuída ao longo do tempo de incubação se mostrou uma característica importante para a sobrevivência da espécie em condições naturais.

Os tratamentos pré-germinativos por 90 e $120 \mathrm{~min}$ proporcionaram emergência rápida e uniforme. Nas unidades de dispersão intactas (testemunha) e nos demais tratamentos há um enorme deslocamento do tempo médio de emergência das plântulas para a direita, evidenciando-se nela uma grande desuniformidade. Também, constatou-se que não ocorreu mais presença de uma moda principal e a emergência de poucas plântulas aparece distribuída por tempo maior.

Os dados de altura das plantas se ajustaram ao modelo quadrático (Figura 6), em que os maiores valores $(26,85 \mathrm{~cm})$ foram obtidos quando as unidades de dispersão foram imersas no ácido sulfúrico concentrado por 95 min. Após as plantas terem atingido a altura máxima, verificou-se redução à medida que aumentou o tempo de imersão das unidades de dispersão no ácido sulfúrico concentrado. Lima e Garcia (1996) verificaram que a imersão de sementes de Acacia mangium Willd. em ácido sulfúrico concentrado por 60 min prejudicou o desenvolvimento das plântulas. Já Sampaio et al. (2001) observaram redução no crescimento de plântulas de Bowdichia virgilioides H.B.K. com a imersão das sementes em ácido sulfúrico concentrado por períodos superiores a $2 \mathrm{~min}$.

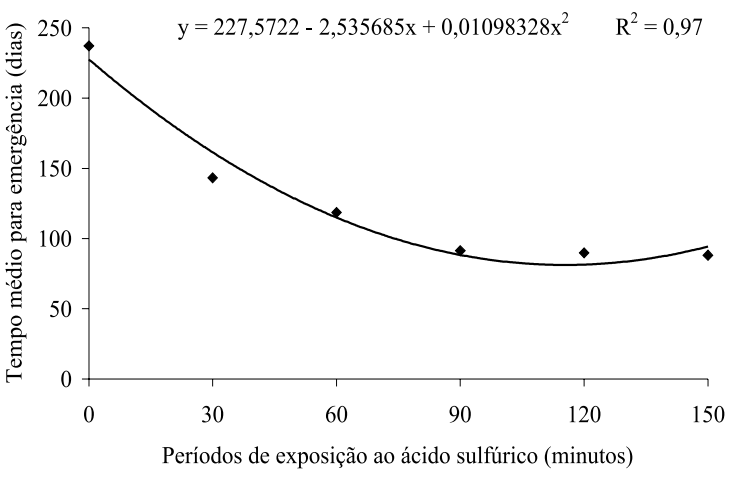

Figura 4 - Vigor de sementes de Zizyphus joazeiro Mart. (tempo médio para germinação), após a superação da dormência das unidades de dispersão com ácido sulfúrico concentrado.

Figure 4 - Vigor of Zizyphus joazeiro Mart. seeds (mean germination time), after breaking dormancy of dispersal units with concentrated sulfuric acid.

R. Árvore, Viçosa-MG, v.30, n.2, p.187-195, 2006 

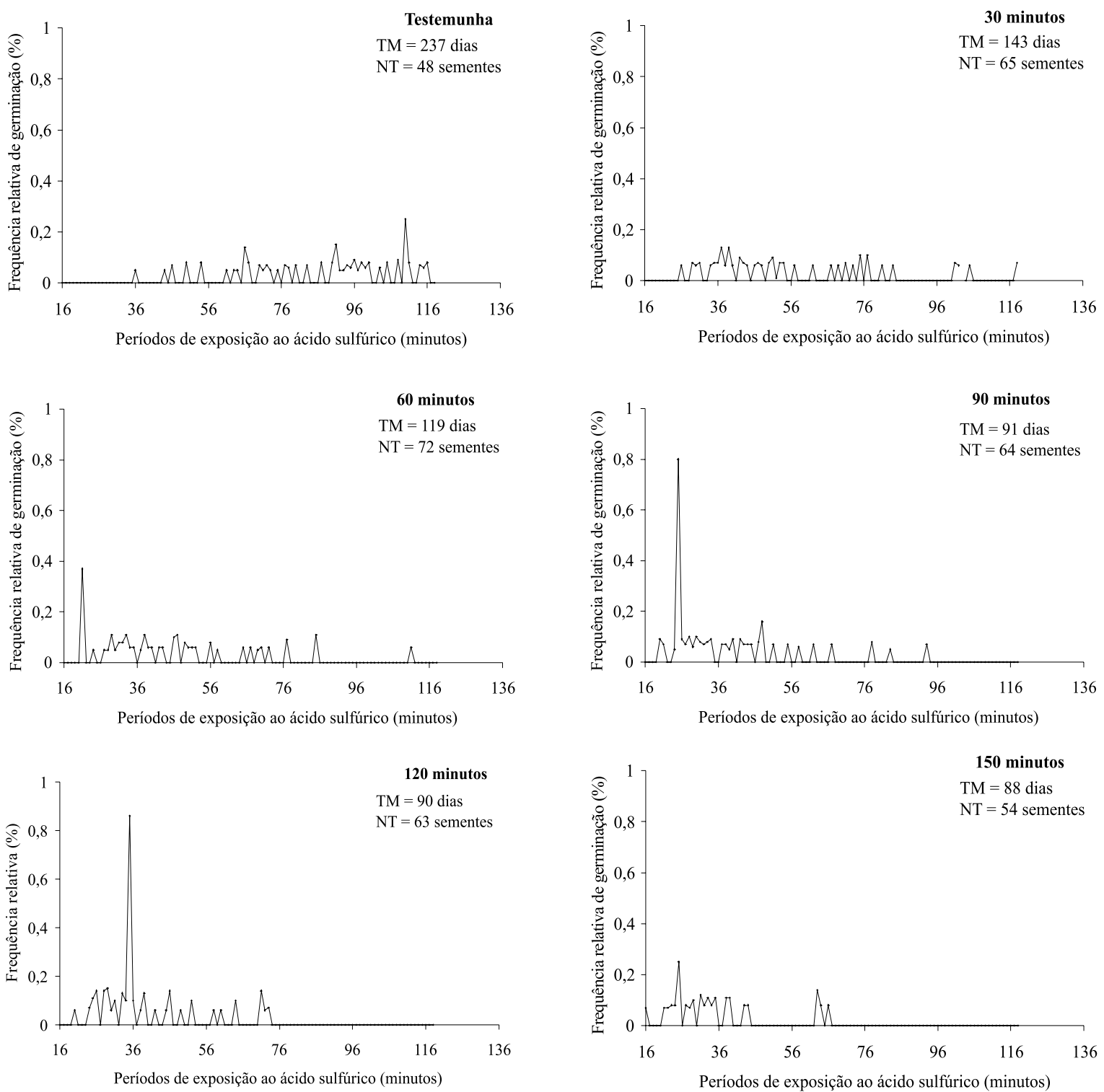

Figura 5 - Polígonos de freqüência relativa de germinação de sementes de Zizyphus joazeiro Mart., após o tratamento das unidades de dispersão com ácido sulfúrico concentrado. TM - Tempo médio para emergência; e NT - Total de plântulas emersas.

Figure 5 - Polygons of relative germination frequency of Zizyphus joazeiro Mart. seeds, after treatment of dispersal units with concentrated sulfuric acid. MT-Mean emergence time; TN-Total of emerged seedlings.

Os dados de massa seca das plantas também se ajustaram ao modelo quadrático (Figura 7), cujos maiores valores $(4,27 \mathrm{~cm})$ foram obtidos quando as unidades de dispersão foram imersas no ácido sulfúrico concentrado por $97 \mathrm{~min}$. Após as plantas terem atingido o máximo conteúdo de massa seca, verificou-se redução à medida que aumentou o tempo de imersão das unidades de dispersão no ácido sulfúrico concentrado. Sementes

R. Árvore, Viçosa-MG, v.30, n.2, p.187-195, 2006 
de Mimosa caesalpiniaefolia Benth. submetidas a tratamentos pré-germinativos com ácido sulfúrico concentrado por 10 ou 13 min originaram plântulas com maior conteúdo de massa seca (BRUNO et al., 2001). Também, Sampaio et al. (2001) verificaram maior conteúdo de massa em plântulas de Bowdichia virgilioides H.B.K. com a imersão das sementes em ácido sulfúrico concentrado por períodos entre $8 \mathrm{e}$ $11 \mathrm{~min}$.

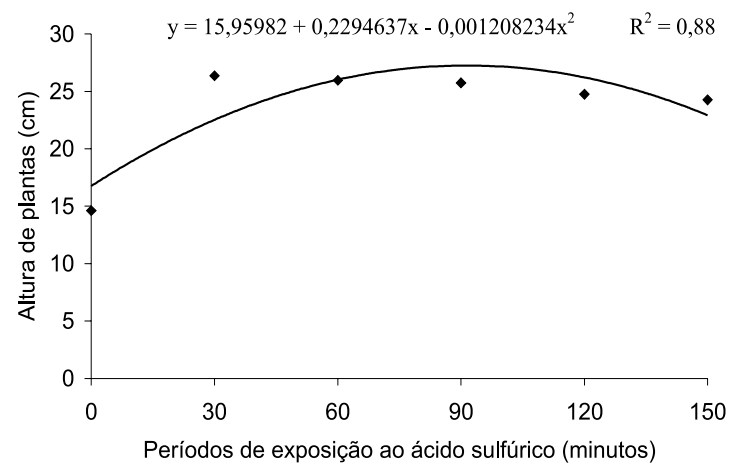

Figura 6 - Altura das plantas de Zizyphus joazeiro Mart., após a superação da dormência das unidades de dispersão com ácido sulfúrico concentrado.

Figure 6 - Height of Zizyphus joazeiro Mart. plants, after breaking dormancy of dispersal units with concentrated sulfuric acid.

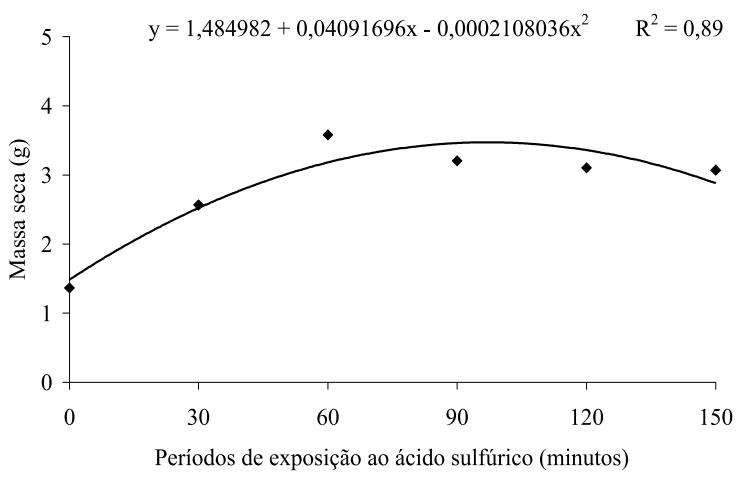

Figura 7 - Vigor de sementes de Zizyphus joazeiro Mart. (massa seca das plantas), após a superação da dormência das unidades de dispersão com ácido sulfúrico concentrado.

Figure 7 - Vigor of Zizyphus joazeiro Mart. seeds (plant dry matter weight), after breaking dormancy of dispersal units with concentrated sulfuric acid.

\section{CONCLUSÃ̃O}

O pré-condicionamento das unidades de dispersão de Zizyphus joazeiro Mart. em ácido sulfúrico concentrado por períodos entre 74 e $115 \mathrm{~min}$ foi eficiente na superação da resistência mecânica, proporcionando maiores resultados de germinação e de vigor.

\section{AGRADECIMENTOS}

Ao CNPq, pela concessão da bolsa de Desenvolvimento Científico Regional (DCR); ao eng.agro. Antônio Alves de Lima e aos laboratoristas Pedro Francisco da Silva, Rui Barbosa da Silva e Severino Francisco dos Santos, por terem viabilizado a execução deste trabalho; e à Profa. Sheilla Costa de Farias, pela correção do abstract.

\section{REFERÊNCIAS BIBLIOGRÁFICAS}

ALVES, M.C.S. et al. Superação da dormência em sementes de Bauhinia monandra Britt e Bauhinia ungulata L. - Caesalpinoideae. Revista Brasileira de Sementes, v.22, n.2, p.139-144, 2000.

BASTOS, G.Q.; NUNES, R.F.; CRUZ, G.M.F. Reavaliação de quebra de dormência em sementes de algarobeira (Prosopis juliflora (Sw.) D.C.).

Revista Brasileira de Sementes, v.14, n.1, p.17-20, 1992.

BRASIL. Ministério da Agricultura e Reforma Agrária. Regras para análise de sementes. Brasília: SNDA/DNDV/CLAV, 1992. 365p.

BRUNO, R.L.A. et al. Tratamentos prégerminativos para superar a dormência de sementes de Mimosa caesalpiniaefolia Benth.

Revista Brasileira de Sementes, v.23, n.2, p.136-143, 2001.

CANDIDO, J.F. et al. Orelha-de-negro (Enterolobium contortisiliquum (Vell.) Morong.): dormência e métodos para sua quebra. Revista Árvore, v.8, n.2, p.104-110, 1982.

CARVALHO, N.M.; NAKAGAWA, J. Sementes: ciência, tecnologia e produção. 4. ed. Jaboticabal: FUNEP, 2000. 588p.

R. Árvore, Viçosa-MG, v.30, n.2, p.187-195, 2006 
CAVALCANTE, A.M.B.; PEREZ, S.C.J.G.A. Efeitos da escarificação química, luz e pH na germinação de sementes de Leucaena leucocephala Lam (De Wit). Revista Ceres, v.43, n.248, p.370-381, 1996.

CÍCERO, S.M. Dormência de sementes. In: SEMANA DE ATUALIZAÇÃO EM PRODUÇÃ̃O DE SEMENTES, 1.. 1986, Campinas. Campinas: Fundação Cargill, 1986. p.41-76.

DUGUMA, B.; KANG, B.T.; OKALI. D.U.U. Factors affecting germination of leucaena (Leucaena leucocephala) (Lam.) de Wit seed. Seed Science and Technology, v.16, n.2, p.489-500, 1988.

EIRA, M.T.S.; FREITAS, R.W.A.; MELLO, C.M.C. Superação da dormência de sementes de Enterolobium contortisiliquum (Vell.) Morong Leguminosae. Revista Brasileira de Sementes, v.15, n.2, p.177-181, 1993.

ELLIS, R.H.; HONG, T.D.; ROBERTS, E.H. Handbook of seed germination for genebanks. Rome: IBPGR, 1985. v.2. p.211-667.

FERREIRA, A.F.; LIPP JOÃO, K.H.; HEUSER, E.D. Efeitos de escarificação sobre a germinação e do pH no crescimento de Acacia bonariensis Gill e Mimosa bimucronata (D.C.) O.K. Revista Brasileira de Fisiologia Vegetal, v.4, n.1, p.63-65, 1992.

FRAZÃO, D.A.C. et al. Escarificação química na emergência de sementes de castanha-do-brasil (Bertholletia excelsa H.B.K.). Revista Brasileira de Sementes, Brasília, v.6, n.1, p.83-90, 1984.

FU, S.M. et al. Breaking hard seed of yellow and slender serradella (Ornithopus compressus e O. pinnatus) by sulphuric acid scarification. Seed Science and Technology, v.24, n.1, p.1-6, 1996.

JELLER, H.; PEREZ, S.C.J.G.A. Estudo da superação da dormência e da temperatura em sementes de Cassia excelsa Schrad. Revista Brasileira de Sementes, v.21, n.1, p.32-40, 1999.

KRAMER, P.J.; KOZLOZWISKI, T.T. Fisiologia das árvores. Lisboa: Fundação Calouste Gulbenkian, 1972. 745p.

R. Árvore, Viçosa-MG, v.30, n.2, p.187-195, 2006
LABOURIAU, L.G.; VALADARES, M.E.B. On the germination of seeds Calotripes procera (Ait.). Anais da Academia Brasileira de Ciências, v.48, n.2, p.263-284, 1976.

LEMOS-FILHO, J.P. et al. Germinação de sementes de Senna macranthera, Senna multijuga e Stryphnodendron polyphyllum. Pesquisa Agropecuária Brasileira, v.32, n.4, p.357-361, 1997.

LIMA, D.; GARCIA, L.C. Avaliação de métodos para o teste de germinação em sementes de Acacia mangium Willd. Revista Brasileira de Sementes, v.18, n.2, p.180-185, 1996.

LOPES, J.C. et al. Germinação de sementes de espécies florestais de Caesalpinea ferrea Mart. ex Tul. var. leiostachya Benth., Cassia grandis L. e Samanea saman Merrill, após tratamento para superar a dormência. Revista Brasileira de Sementes, v.20, n.1, p.80-86, 1998.

LOPEZ, J.H.; AVILES R.B. The pretreatment of seeds of four Chilean prosopis to improve their germination response. Seed Science and Technology, v.16, n.1, p.239-240, 1988.

LORENZI, H. Árvores brasileiras: manual de identificação e cultivo de plantas arbóreas nativas do Brasil. 3.ed. Nova Odessa: Instituto Plantarum, 2000. v. 1.351p.

MAEDA, J.A.; MARCONDES COELHO, S.M.B. Germinação e dormência de sementes de framboesa (Rubus idaeus L.). Revista Brasileira de Sementes, v.17, n.1, p.101-106, 1995.

MAGUIRE, J.D. Speed of germination aid in selection and evaluation for seedling emergence and vigor. Crop Science, v.2, n.2, p.176-177, 1962.

MARTINS, C.C.; CARVALHO, N.M.; OLIVEIRA, A.P. Quebra de dormência de sementes de sabiá (Mimosa caesalpiniaefolia Benth.). Revista Brasileira de Sementes, v.14, n.1, p.5-8, 1992.

MAYER, A.M.; POLJAKOFF-MAYBER, A. The germination of seeds. 4.ed. New York: Pergamon Press, 1989. 270p.

R. Arvore, Vicosa-MG, v.30, n.2, p.187-195, 2006 
PASSOS, M.A.A.; LIMA, T.V.; ALBUQUERQUE, J.L. Quebra de dormência de sementes de leucena. Revista Brasileira de Sementes, v.10, n.2, p.97-102, 1988.

PEREZ, S.C.J.G.A.; PRADO, C.H.B.A. Efeitos de diferentes tratamentos pré-germinativos e da concentração de alumínio no processo germinativo de sementes de Copaifera langsdorfii Desf. Revista Brasileira de Sementes, v.15, n.1, p.115-118, 1993.

PEREZ, S.C.J.G.A.; FANTI, S.C.; CASALI, C.A. Dormancy break and light quality effects on seed germination of Peltophorum dubium Taub.

Revista Árvore, v.23, n.2, p.131-137, 1999.

POPINIGIS, F. Fisiologia da semente. 2. ed. Brasília: ABRATES, 1985. 298p.

REISMAN-BERMAN, O.; KIGEL, J.; RUBIN, B. Dormancy patterns in buried seeds of Datura ferox and D. stramonium. Canadian Journal of Botany, v.69, n.1, p.173-179, 1991.

RIBAS, L.L.F.; FOSSATI, L.C.; NOGUEIRA,A.C. Superação da dormência de sementes de Mimosa bimucronata (D.C.) O.Kuntze (maricá). Revista Brasileira de Sementes, v.18, n.1, p.98-101, 1996.
ROLSTON, M.P. Water impermeable seed dormancy. The botanical Review, v.44, n.33, p.365-396, 1978.

SAMPAIO, L.S.V. et al. Ácido sulfúrico na superação da dormência de sementes de sucupirapreta (Bowdichia virgilioides H.B.K. - Fabaceae). Revista Brasileira de Sementes, v.23, n.1, p.184-190, 2001.

SANTARÉM, E.R.; AQUILA, M.E.A. Influência de métodos de superação de dormência e do armazenamento na germinação de sementes de Senna macranthera (Colladon) Irwin \& Barneby (Leguminosae). Revista Brasileira de Sementes, v.17, n.2, p.205-209, 1995.

TODD-BOCKARIE, A.H. et al. Pretreatment to overcome seed coat dormancy in Cassia sieberiana. Seed Science and Technology, v.21, n.2, p.383-398, 1993.

VAZQUEZ-YANES, C.; OROZCO-SEGOVIA,A. Patterns of seed longevity and germination in the tropical rainforest. Annual Review of ecology and Systematics, v.24, p.69-87, 1993. 